\title{
Prediction of Surface Roughness for HSM Based on BP Neural Network
}

\author{
Ying Chen ${ }^{\mathrm{a}}$, Yanhong Sun ${ }^{\mathrm{b}^{*}}$, Zhenwen $\mathrm{Yang}^{\mathrm{c}}$ and Guangdong $\mathrm{Wu}^{\mathrm{d}}$ \\ College of Mechanical Engineering, Jilin Engineering Normal University, \\ Changchun 130052, China

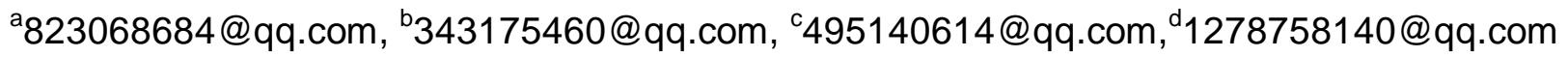 \\ *The corresponding author
}

Keywords: Surface roughness; BP neural network; Cutting parametres; 5-axis machine; Toroidal cutter

\begin{abstract}
A predictive model is presented for the surface roughness in high-speed milling of P1.2738 (plastic die steel)based on BP Neural network. The data for establishing the model is derived from the experiment conducted on a high-speed 5-axis machining center by factorial design of experiments. Compared with measured data and data from regression analysis, the result of prediction using BP neural network indicates its feasibility, which provides reference for the optimization of cutting parameters.
\end{abstract}

\section{Introduction}

Surface roughness is an important parameter to evaluate the surface quality of high speed finishing. There are many influencing factors, in which the selection of cutting parameters is the main factor, especially the relationship between the values of cutting parameters is very important to the surface roughness. The high speed cutting process is complicated, so it is difficult to establish an analytical model because it needs many parameters to be controlled and difficult to match with the actual conditions. Therefore, through the cutting test, the empirical prediction model of surface roughness based on BP neural network is established, which provides a reliable basis for reasonable selection of milling parameters.

\section{Orthogonal Test and Data Analysis}

\section{Test Conditions.}

Test equipment: DMU125P five axis milling machine

Cutter: toroidal cutter with a diameter of 25

Workpiece material: P1.2738 plastic mould steel

Cooling method: oil mist

Measuring instrument: measuring instrument of surface roughness, each parameter test result is measured 10 times, taking mean value

Test Scheme. The orthogonal test method to test the number of main contradiction may be less exhausted by the orthogonal table to find the influencing factors of the comprehensive comparison and statistical analysis, this test mainly aims at cutting parameters (spindle speed): cutting speed, feed rate and cutting depth, the radial feed, tool diameter and other conditions in the premise as the known conditions of the surface roughness, using four factors and four levels orthogonal table (second column is empty column). Table 1 presents the table of factors, and the results are shown in table 1.

\section{Prediction Model of Surface Roughness Based on BP Network}

BP network is a multilayer feedforward neural network, which uses nonlinear differentiable function to train weights. It can build prediction model with neural network technology by means of computer's 
Table 1 Level of four factor and four level test factor

\begin{tabular}{ccccc}
\hline & \multicolumn{4}{c}{ test factor } \\
\cline { 2 - 5 } level & $\begin{array}{c}\text { Milling } \\
\text { depth } \\
a_{p}[\mathrm{~mm}]\end{array}$ & $\begin{array}{c}\text { Spindle speed } \\
n[r / \mathrm{min}]\end{array}$ & $\begin{array}{c}\text { Feed per tooth } \\
f_{z}[\mathrm{~mm} / r]\end{array}$ & $\begin{array}{c}\text { Milling } \\
\text { spacing } \\
a_{e}[\mathrm{~mm}]\end{array}$ \\
\hline 1 & 0.05 & 6000 & 0.05 & 2 \\
2 & 0.10 & 6500 & 0.10 & 4 \\
3 & 0.15 & 7000 & 0.15 & 6 \\
4 & 0.20 & 7500 & 0.20 & 8 \\
\hline
\end{tabular}

fast computing and processing ability. To solve complex nonlinear problems, the output values of approximate actual machining results can be obtained. In this paper, a prediction model for surface roughness of high speed machining is constructed by using BP network.

Input and Output Data and Preprocessing. The feed forward BP network type $S$ transform function to avoid network activation in the flat area of the work function data should be transformed into $[0.1,0.9]$, for the convenience of network identification in network prediction and execution of input and output parameters were normalized. In the network prediction, in order to make the output more close to the actual requirements, the output vector should be treated by inverse normalization.

Network Parameter Setting. The neural network in this paper uses three layers of network structure with 4 inputs, 1 outputs and 1 hidden layers. The structure of the neural network is shown in figure 1 . The 4 input vectors are milling speed, radial milling depth, axial milling depth and feed per tooth, and the output layer vector is surface roughness.

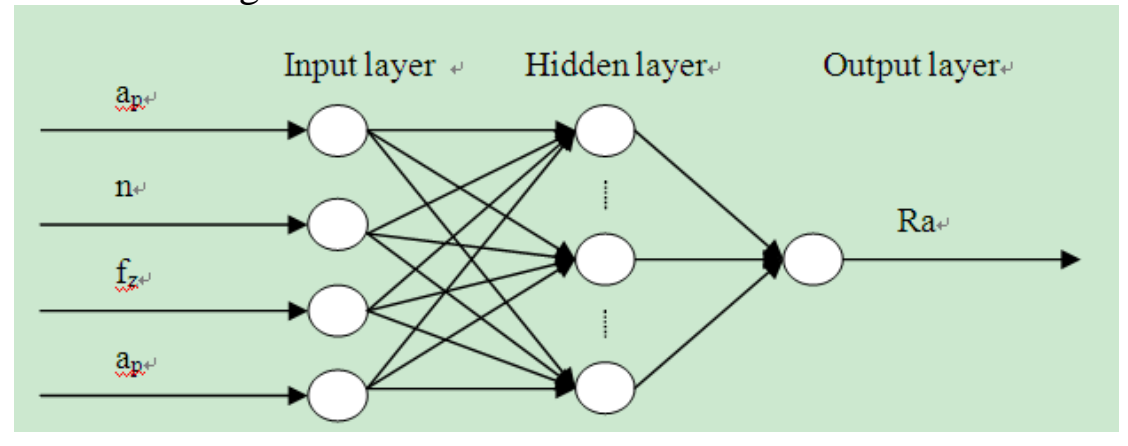

Figure.1 Neural network structure diagram

In this paper, the BP neural network with one hidden layer is used, and the number of hidden nodes is determined by the method of trial and error according to approximation error and generalization error. The other parameters are shown in Table 2.

Table 2 Parameters settings of neural network

\begin{tabular}{|c|c|c|c|c|c|c|c|}
\hline \multicolumn{2}{|c|}{ Transfer function } & \multirow{2}{*}{$\begin{array}{c}\quad \text { traini } \\
\text { ng } \\
\text { Function }\end{array}$} & \multirow{2}{*}{$\begin{array}{l}\text { initial } \\
\text { learning } \\
\text { rate }\end{array}$} & \multirow{2}{*}{$\begin{array}{l}\text { learni } \\
\text { ng growth } \\
\text { rate }\end{array}$} & \multirow[b]{2}{*}{$\begin{array}{l}\text { drop } \\
\text { rate }\end{array}$} & \multirow{2}{*}{$\begin{array}{l}\text { momen } \\
\text { tum } \\
\text { Factor }\end{array}$} & \multirow{2}{*}{$\begin{array}{c}\text { Maxi } \\
\text { mum } \\
\text { training } \\
\text { times }\end{array}$} \\
\hline $\begin{array}{l}\text { Hidden } \\
\text { layer }\end{array}$ & $\begin{array}{l}\text { outpu } \\
\text { t layer }\end{array}$ & & & & & & \\
\hline $\begin{array}{l}\text { Hyperbo } \\
\text { lic tangent }\end{array}$ & linear & LM & 0.01 & 1.0 & 0.7 & 0.02 & 3000 \\
\hline
\end{tabular}

\section{Training and Verification of Neural Networks}

In the 16 sets of data in this paper, 14 groups are selected as training samples, and the remaining 2 groups are used as verification samples. In the course of network training, the number of hidden nodes is constantly adjusted, and when the number of hidden nodes is 12 , the network error tends to be stable, and the training process of the model is over. The network model trained by the mean square error trend with the increase of the number of the training steps as shown in Figure 2, when the network training MSE network training model steps and achieve the fifteenth step network model meet the requirements . 


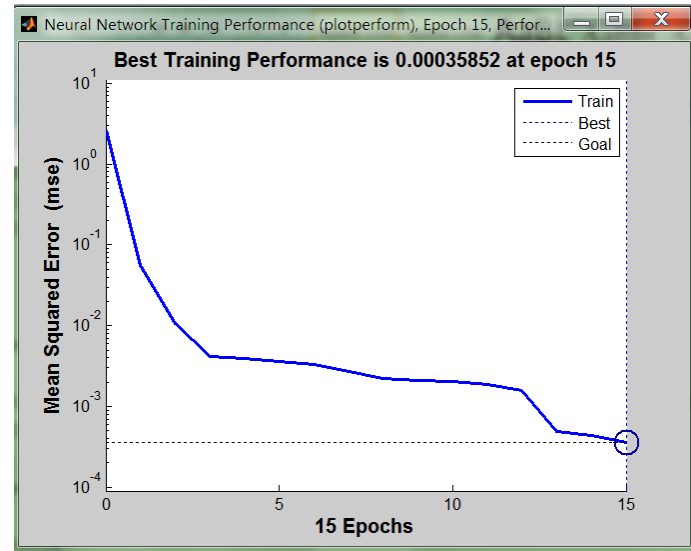

Figure 2. Relation between training steps and training error

After the end of the training needs of network training has been good model for testing until the generalization error satisfies the predefined requirements in order to validate the generalization ability of the model, the generalization error for the preservation of network model 0.004236 , otherwise the need for re training network. The prediction results and errors of training samples and test samples are shown in Table 2. The prediction values and their corresponding error values of the orthogonal regression method are also listed in the table.

The range analysis method can only determine the surface roughness with milling parameters variation in a given parameter for a group of optimal parameters and not on its forecast; in the orthogonal regression analysis and prediction model based on BP algorithm, through the forecast comparison can be seen as the average prediction error of regression analysis $7.8156 \%$, BP algorithm samples the average error is $2.6285 \%$, significantly higher than that of $\mathrm{BP}$, which also shows that the BP model is more effective.

\section{Data Analysis}

Considering the interaction between speed and feed rate, a multiple linear regression model was established, and the results of BP neural network prediction and regression analysis were compared.

Multivariate Linear Regression Model.

$$
R a=10^{0.7279} a_{p}^{0.0720} n^{-0.2449} f_{z}^{0.2903} a_{e}^{0.1912}=7.9524 a_{p}^{0.0720} n^{-0.1967} f_{z}^{0.2903} a^{0.1912}
$$

Comparison of BP Neural Network Prediction and Regression Analysis. The prediction results and errors of training samples and test samples are shown in Table 3. The prediction values and their corresponding error values of the orthogonal regression method are also listed in the table.

Table 3 Prediction results and errors

\begin{tabular}{|c|c|c|c|c|c|}
\hline \multirow[b]{2}{*}{ No. } & \multicolumn{5}{|c|}{ surface roughness $(\mathrm{um})$} \\
\hline & Measured & relative & $\begin{array}{l}\text { error of orthogonal } \\
\text { prediction }(\%)\end{array}$ & BP prediction & relative error (\%) \\
\hline 1 & 0.434 & 0.3723 & 14.22 & 0.4340 & 0 \\
\hline 2 & 0.536 & 0.5117 & 4.53 & 0.5679 & 5.95 \\
\hline 3 & 0.599 & 0.6130 & -2.34 & 0.5679 & 5.19 \\
\hline 4 & 0.682 & 0.6946 & -1.85 & 0.6821 & 0.01 \\
\hline 5 & 0.664 & 0.6909 & -4.05 & 0.6610 & 0.45 \\
\hline 6 & 0.743 & 0.7221 & 2.81 & 0.7178 & 3.39 \\
\hline 7 & 0.389 & 0.4277 & -9.95 & 0.3925 & 0.91 \\
\hline 8 & 0.378 & 0.4643 & -22.83 & 0.3820 & 1.06 \\
\hline 9 & 0.654 & 0.6675 & -2.06 & 0.5940 & 9.18 \\
\hline 10 & 0.610 & 0.5306 & 13.02 & 0.6640 & 5.58 \\
\hline 11 & 0.631 & 0.6424 & -1.81 & 0.6487 & 2.81 \\
\hline 12 & 0.434 & 0.4894 & -12.76 & 0.4325 & 0.34 \\
\hline 13 & 0.723 & 0.5941 & 17.83 & 0.6948 & 3.89 \\
\hline 14 & 0.535 & 0.5203 & 2.75 & 0.5356 & 0.11 \\
\hline 15 & 0.555 & 0.6056 & -9.12 & 0.5550 & 0 \\
\hline 16 & 0.667 & 0.6462 & 3.12 & 0.6400 & 4.05 \\
\hline $\begin{array}{l}\text { Average } \\
\text { error }\end{array}$ & & & 7.8156 & & 2.6825 \\
\hline
\end{tabular}


In the orthogonal regression analysis and prediction model based on BP algorithm, the average prediction error by the comparison of predicted visible regression analysis was $7.8156 \%$, BP algorithm samples the average error is $2.6285 \%$, significantly higher than that of $\mathrm{BP}$, which also shows that the BP model is more effective.

\section{Conclusion}

The data processing capacity of multi condition and method of artificial neural network based on multi factors, BP neural network based nonlinear model of surface roughness in high speed milling of this paper and the network prediction results and orthogonal regression method, it is concluded that the BP network algorithm has better prediction ability, and the various factors on the surface roughness and the impact of the range analysis is consistent.

\section{References}

[1] H. Erdim, I. Lazoglu and B. Ozturk: International Journal of Machine Tools and Manufacture, Vol. 46 (2006) Issues 7-8: p.747.

[2] J.S.Yang, H.W.Guo and J.S. Yang: Mechanical manufacturing and research, 2011,40 (3), 34-35,p.104.

[3] Stephen Mann, Sanjeev Bedi: Computer-Aided Design, 2002, No.34,p.373.

[4] Li-Xin Cao, Hu Gong, Jian Liu: Journal of Materials Processing Technology, 2007, 184,p.6.

[5] N.Baskar, P.Asokan,R, Saravanan: Int j Adv Manuf Technol 2005(26),p.1202.

[6]W. Wang, S. Tang and Y. Y. Zhang: Mechanical design and manufacturing, 2010 No.3,p.216.

[7]M. L. Tian, Z.J.Li and B.Yan: Tool technology, 2004,42(3),p.35.

[8]Y. Fang, F.Q. Li: Tool technology, 2006, 40(11),p.78.

[9]S.Y. Wang, X. Ai and J. Zhao: Manufacturing technology and machine tools, 2006 No.8,p.65.

[10]Z.Y. Hu, G.J. Meng and H.T. Hai: Manufacturing technology and machine tools, 2011 No.1,p.44. 